\title{
Study of various treatment modalities of caesarean scar pregnancy
}

\author{
Prachi Meghani*, Sapana R. Shah, Rupa C. Vyas, Purvi M. Parikh, Tanmay J. Chudasama
}

Department of Obstetrics and Gynecology, NHL Municipal Medical College, Ahmedabad, Gujarat, India

Received: 24 November 2021

Accepted: 23 December 2021

\author{
*Correspondence: \\ Dr. Prachi Meghani, \\ E-mail: prachimeghani2896@gmail.com
}

Copyright: () the author(s), publisher and licensee Medip Academy. This is an open-access article distributed under the terms of the Creative Commons Attribution Non-Commercial License, which permits unrestricted non-commercial use, distribution, and reproduction in any medium, provided the original work is properly cited.

\begin{abstract}
Background: Caesarean scar pregnancy (CSP) can be defined as the implantation of the gestational sac within the scar of a previous caesarean surgery. Incidence of CSP is 1 in 1800 pregnancies.

Methods: It is a retrospective study based on clinical diagnosis and management of CSP of women who presented to the obstetrics and gynaecology department SVP hospital from January 2008 to August 2021. Total number of cases of CSP were 28. Incidence, gestational age, ultrasound findings, serum $\beta$-human chorionic gonadotropin ( $\beta$-hCG) levels, flow profiles of color Doppler, and different methods of treatment were recorded. Diagnosis was confirmed by ultrasound.

Results: In this study, all 28 cases of CSP considered were offered definitive management. In present study 5 cases $(17.88 \%)$ showed torrential haemorrhage during dilatation and evacuation (D and E) which was treated by various methods like 1 (3.57\%) Foley's tamponade, 1 (3.57\%) uterine artery embolization (UAE) and 3 (10.71\%) hysterectomy. Hysterotomy was performed in 13 cases $(46.42 \%)$ and $(7.69 \%)$ of heterotrophic CSP (HCSP). One case (3.84\%) of CSP presented at 26 weeks of gestation with haemorrhagic shock, underwent obstetric hysterectomy.

Conclusions: There is a rise in the incidence of CSP because of increase in the global rate of caesarean sections and early transvaginal USG in pregnancy. Transvaginal sonography is the best diagnostic tool. Medical management can be offered when diagnosis is made at gestational age of $<7$ weeks. Whereas, surgical modalities have shown better results at $>7$ weeks of gestational age. Surgical management has an advantage of shorter follow up.
\end{abstract}

Keywords: CSP, Placenta accreta spectrum, Color doppler

\section{INTRODUCTION}

Caesarean scar pregnancy (CSP) can be defined as the implantation of the gestational sac within the scar of a previous caesarean surgery. It represents $6 \%$ of all ectopic pregnancies in women with at least one previous lower uterine segment caesarean section. Incidence of CSP is 1 in 1800 pregnancies. ${ }^{1}$ This is related to the increase in the number of caesarean deliveries.

There are several hypotheses proposed for CSP. Vial et al found two different types of CSP. First type of CSP is the implantation of conceptus on the previous caesarean scar and it grows towards the cervico-isthmic space or the uterine cavity. This type of CSP, if untreated, may grow up to term, develops placenta accreta spectrum (PAS) disorder with the risk of torrential haemorrhage and end up in peripartum hysterectomy. Second type of CSP is a deep implantation into a caesarean scar defect, and it grows towards the urinary bladder and abdominal cavity. ${ }^{2}$ Second type of CSP is more prone to rupture. Another hypothesis argues that the conceptus enters the myometrium through a microscopic dehiscent tract or defect in the caesarean section scar.

The difficult part is to decide a treatment plan on a subject as the treatment is not standardized, and there are no generally accepted guidelines worldwide. The woman who demands continuation of pregnancy is to be counselled regarding development of PAS disorders in the third trimester and increased risk of maternal morbidity and mortality. ${ }^{3}$ 


\section{Aims and objectives}

Aim and objectives of the study were to facilitate early diagnosis of CSP and choosing its correct modality of treatment.

\section{METHODS}

This is an observational, retrospective study based on clinical diagnosis and management of CSP of women who reported to the department of obstetrics and gynaecology at SVP hospital, Smt. NHL Municipal Medical college, from January 2008 to August 2021. The results obtained by using jmp software. Total number of cases of CSP were 28 which were diagnosed using transvaginal sonography and color doppler. Data was collected from the case files of patients with CSP which were traced through indoor case records and operation theatre registers. Incidence, gestational age, ultrasound findings, serum $\beta$-human chorionic gonadotropin ( $\beta$-hCG) levels, flow profiles of color doppler, and different methods of treatment were recorded. Diagnosis was confirmed in all cases with standard sonographic criteria: ${ }^{4}$ (1) Empty uterine cavity, with clearly demonstrated endometrium, (2) Empty cervical canal, (3) Presence of the gestation sac with or without a fetal pole, with or without fetal cardiac activity (depending on the gestational age) in the anterior part of the isthmic portion of uterus, (4) Thinned out/an absence of normal myometrium between the urinary bladder wall and the gestational sac and (5) Color Doppler shows high velocity with low impedance peri-trophoblastic vascular flow clearly surrounding sac (PSV $>15 \mathrm{~cm} / \mathrm{sec}$ ).

\section{Exclusion criteria}

This includes the cases which do not abide by ultrasound criteria.

\section{RESULTS}

Among 28 cases, 24 cases $(85.7 \%)$ belonged to the age group of 21-40 years.

Table 1: Age distribution of patients.

\begin{tabular}{|ll|}
\hline Age (years) & No. of patients $(\%)$ \\
\hline $\mathbf{2 0}$ & $2(7.14)$ \\
\hline $\mathbf{2 1 - 4 0}$ & $24(85.7)$ \\
\hline$>\mathbf{4 0}$ & $2(7.14)$ \\
\hline
\end{tabular}

Maturity ranges from 5 weeks to 11 weeks +6 days. The duration from the last cesarean section ranged from 5 months-10 years at diagnosis.

Nine cases were selected for medical management. One case was treated with local injection methotrexate (MTX) under USG guidance. Four cases were given single dose IM MTX. Four cases were given multiple doses of MTX, out of which 1 case developed drug toxicity after $3^{\text {rd }}$ dose resulting in renal dysfunction and bone marrow suppression which was managed by leucovorin and granulocyte-colony stimulating factor (GCSF). The scar pregnancy mass took 2 months to 10 months' time for regression even after normal values of $\beta$-hCG are reached.

Five cases which were treated by $\mathrm{D}$ and $\mathrm{E}$ in the initial part of study period, as first line management had profuse vaginal bleeding. Three cases required hysterectomy to control torrential haemorrhage and one of them managed with foleys' catheter balloon tamponade successfully and other required UAE.

Thirteen cases required surgery due to persistent pain and recurrent bleeding, gestational age $>7$ weeks and presence of fetal cardiac activity were successfully managed by hysterotomy (12-laparotomy, 1-laparoscopy)- local resection of ectopic mass, excision of fibrous edges of hysterotomy incision and suturing.

There was severe haemorrhage in 4 cases which was controlled by bilateral uterine artery ligation by O'Leary technique and required blood transfusion.

In other 4 cases, as ectopic mass was large, prophylactically uterine artery ligation was done before hysterotomy incision.

One case was diagnosed at 5 weeks of gestation and the patient didn't get admitted for treatment and later came with severe bleeding per vaginum at 26 weeks of gestation. On USG, she had central placenta previa with PAS disorder and needed Obstetric hysterectomy.

Table 2: Various modes of treatment of CSP.

\begin{tabular}{|c|c|c|}
\hline Mode of management & $\begin{array}{l}\text { Present } \\
\text { study }(\%)\end{array}$ & $\begin{array}{l}\text { Jurkovic } \\
\text { et } \mathbf{a l}^{10}(\%)\end{array}$ \\
\hline Expectant & - & $23(9.9)$ \\
\hline Local MTX & $1(3.57)$ & $7(3)$ \\
\hline \multicolumn{3}{|l|}{ Systemic MTX } \\
\hline Single dose & $4(14.28)$ & - \\
\hline Multiple dose & $4(14.28)$ & - \\
\hline $\mathrm{D}$ and $\mathrm{E}$ & $5(17.88)$ & $104(54.5)$ \\
\hline $\begin{array}{l}\text { D and E + Shirodkar's } \\
\text { cervical suture }\end{array}$ & C् & $82(42.9)$ \\
\hline $\begin{array}{l}\mathrm{D} \text { and } \mathrm{E}+\text { foley's } \\
\text { tamponade }\end{array}$ & $1(3.57)$ & - \\
\hline $\mathrm{D}$ and $\mathrm{E}+\mathrm{UAE}$ & $1(3.57)$ & - \\
\hline Preoperative UAE & - & $1(0.5)$ \\
\hline $\begin{array}{l}\mathrm{D} \text { and } \mathrm{E} \text { followed by } \\
\text { hysterectomy }\end{array}$ & $3(10.71)$ & - \\
\hline $\begin{array}{l}\text { Foley's tamponade as } \\
\text { primary treatment }\end{array}$ & - & $3(1.6)$ \\
\hline $\begin{array}{l}\text { Cervical suture }+ \text { Foley's } \\
\text { catheter }\end{array}$ & - & $1(0.5)$ \\
\hline \multicolumn{3}{|l|}{ Hysterotomy } \\
\hline Laparotomy & $12(42.85)$ & - \\
\hline Laparoscopy & $1(3.57)$ & - \\
\hline Hysterectomy & $1(3.57)$ & $1(0.5)$ \\
\hline
\end{tabular}


Out of 28 cases, hysterectomy was required in 4 cases.

In a study by Jurkovic et al 23 cases $(9.9 \%)$ were managed by expectant management, 7 cases $(3 \%)$ were treated by local MTX. The 104 cases $(54.5 \%)$ were treated by D and $\mathrm{E}$ alone, while 82 cases (42.9\%) were managed with D and $\mathrm{E}$ in addition to Shirodkar's cervical suture. ${ }^{10}$ One case $(0.5 \%)$ had to undergo preoperative UAE. In 3 cases $(1.6 \%)$, Foley's catheter was used as a primary treatment option. In 1 case $(0.5 \%)$, Foley's catheter was used in addition to Shirodkar's cervical suture. One case $(0.5 \%)$ had to undergo hysterectomy due to uncontrolled haemorrhage.

\section{DISCUSSION}

In this study, all 28 cases of CSP considered were offered definitive management. There is no place for expectant management in viable pregnancy. ${ }^{5}$ There are different modalities of management of CSP. Nine (32.14\%) cases received MTX as the primary treatment effectively with following criteria: $G$ sac $<7$ week, $\beta$-HCG level $<5,000 \mathrm{IU} / \mathrm{L}$, mass diameter $<25 \mathrm{~mm}$, no cardiac action of embryo and the presence of the myometrium between the Gestational-Sac and bladder wall.

The standard single dose regimen of MTX is $50 \mathrm{mg} / \mathrm{m}^{2}$. The multiple dose regimen includes four doses of MTX 1 $\mathrm{mg} / \mathrm{kg}$ given on days $1,3,5$ and 7 with alternating days (2, 4, 6 and 8) folinic acid $0.1 \mathrm{mg} / \mathrm{kg}$ to avoid side effects of MTX. According to a study by Jurkovic et al, $8(44 \%)$ women with CSP were initially treated surgically, 7 (39\%) medically and $3(17 \%)$ underwent expectant management. ${ }^{10}$ Surgical management was successful in all cases. While in present study, $9(32.14 \%)$ were treated medically and $19(67.86 \%)$ required surgical intervention. Medical management was $100 \%$ successful in present study. A review of medical treatment by Bij de Vate et al. ${ }^{6}$ showed that only $16 / 38$ (42\%) women had successful primary treatment with local or systemic MTX. Lian et al reported failure of single-dose systemic MTX in 12/21 cases $(57 \%)$ requiring additional doses of MTX or surgical intervention. ${ }^{7}$

D and E should not be used as a primary treatment. ${ }^{8}$ It is also evident from present study that in 5 out of 28 cases $(17.88 \%)$ there was torrential haemorrhage during D and $\mathrm{E}$ which had to be treated by various methods like 1 (3.57\%) Foley's tamponade, $1(3.57 \%)$ UAE and 3 $(10.71 \%)$ hysterectomy.

Hysterotomy is the standard and definitive treatment and was performed in 13 out of 28 cases $(46.42 \%)$ in our study. Laparoscopy-minimal invasive surgery is the first choice of treatment, but surgeon must be trained and skilled in endoscopy and theatre must be having endoscopy set up. In 2013, Wang et al reported that 11 patients with CSP underwent successful laparoscopic bilateral uterine artery ligation and resection of the scar with gestational tissue and wound repair or laparoscopic bilateral uterine artery ligation combined with transvaginal resection of the scar with gestational tissue and wound repair with preservation of uterus. ${ }^{9}$

In present study, 1 case $(3.84 \%)$ of CSP which was diagnosed at 5 weeks of gestation but the patient did not turn up, later presented at 26 weeks of gestation with haemorrhagic shock. It was diagnosed as central placenta previa with PAS disorder on USG and the patient underwent urgent obstetric hysterectomy.

Out of 13 cases, hysterotomy was done in 2 cases $(7.69 \%)$ of heterotrophic CSP (HCSP). One case of previous 2 caesarean sections was treated by evacuation of both intrauterine and extrauterine gestational sacs via laparotomy at 12 weeks. Another case of HCSP diagnosed at 7 weeks of gestation was treated with injecting local $\mathrm{KCL}$ (potassium chloride) in the extrauterine pregnancy, but on follow up after 48 hours there was absent cardiac activity even in the intrauterine pregnancy. Due to persistent symptoms of pain and bleeding per vaginum, she was then treated with hysterotomy via laparotomy.

Jurkovic et al performed cervical suture (Shirodkar's) mainly in women with live pregnancy $\geq 8$ weeks' gestation and in failing pregnancies that appeared moderately or extremely vascular on preoperative Doppler examination. Continuous bleeding from the implantation site after evacuation of CSP usually led to the formation of hematometra, that could be seen in USG. Intravenous ergometrine $(500 \mu \mathrm{g})$ was administered to induce uterine contraction and to facilitate tamponade of the implantation site by blood clots retained inside the uterine cavity. ${ }^{10}$ The success of the Shirodkar suture can be explained by a more effective tamponade of the implantation site achieved by the blood clot. The bleeding into the uterine defect enforces an even distribution of pressure on the defective myometrium. The most important advantage of using cervical suture is that, by fastening the knot, haemostasis is instant and complete and the success rate was $100 \%$. Newer treatment modality with double balloon catheter conducted by Timor Tritsch showed 100\% successful results in cases of CSP with gestational age of 6-8 weeks with preservation of fertility. ${ }^{11}$ This method has 4 main advantages: it effectively stops embryonic cardiac activity, prevents bleeding, does not require any additional invasive therapies, and is acquainted to obstetriciansgynaecologists who use the same cervical ripening catheters for labour induction.

\section{Limitations}

This study is simple observational study and so we are unable to apply any statistical test of significance.

\section{CONCLUSION}

There is a rise in the incidence of CSP because of increase in the global rate of caesarean sections and early transvaginal USG in pregnancy. Transvaginal sonography 
and colour Doppler ultrasound are the best diagnostic tools for its detection, and if needed, for treatment as well. Early diagnosis is crucial for better prognosis. Medical management can be offered when diagnosis is made at gestational age of $<7$ weeks. Whereas, surgical modalities have shown better results if presentation is at $>7$ weeks of gestational age. Patients diagnosed with CSP in the first trimester should be counselled regarding the possible second and third trimester complications such as PAS with its possible consequences. Surgical management has an advantage of shorter follow up and is a definitive modality of treatment when gestational age is beyond 7 weeks.

Funding: No funding sources

Conflict of interest: None declared

Ethical approval: The study was approved by the Institutional Ethics Committee

\section{REFERENCES}

1. Rotas M, Haberman S, Levgur M. Cesarean scar ectopic pregnancies: aetiology, diagnosis, and management. Obstet Gynecol. 2006;107(6):1373-81.

2. Vial Y, Petignat P, Hohlfeld P. Pregnancy in a cesarean scar. Ultrasound Obstet Gynecol. 2000;16(6):592-3.

3. El Gelany S, Mosbeh MH, Ibrahim EM. Placenta Accreta Spectrum (PAS) disorders: incidence, risk factors and outcomes of different management strategies in a tertiary referral hospital in Minia, Egypt: a prospective study. BMC Pregnancy Childbirth. 2019;19(1):313.

4. Seow KM, Huang LW, Lin YH. Cesarean scar pregnancy: issues in management. Ultrasound Obstet Gynecol. 2004;23(3):247-53.
5. Bodour S. The efficacy of the systemic methotrexate treatment in caesarean scar ectopic pregnancy: A quantitative review of English literature. J Obstet Gynaecol. 2015;35(3):290-6.

6. Bij de Vaate AJ, Huirne JA, Van der Slikke JH. Medical treatment of cesarean scar pregnancy. J Minim Invasive Gynecol. 2010;17:133.

7. Lian F, Wang Y, Chen W. Uterine artery embolization combined with local methotrexate and systemic methotrexate for treatment of cesarean scar pregnancy with different ultrasonographic pattern Cardiovasc Intervent Radiol. 2012;35:286-91.

8. Wang CB, Tseng CJ. Primary evacuation therapy for Cesarean scar pregnancy. Ultrasound Obstet Gynecol. 2006;27(2):222-6.

9. Wang HY, Zhang J, Li YN. Laparoscopic management or laparoscopy combined with transvaginal management of type II cesarean scar pregnancy. JSLS. 2013;17(2):263-72.

10. Jurkovic D, Ben-Nagi J, Ofilli-Yebovi D. Efficacy of Shirodkar cervical suture in securing haemostasis following surgical evacuation of Cesarean scar ectopic pregnancy. Ultrasound Obstet Gynecol. 2007;30(1):95-100.

11. Timor-Tritsch IE, Monteagudo A, Cali G. Cesarean scar pregnancy is a precursor of morbidly adherent placenta. Ultrasound Obstet Gynecol. 2014;44(3):346-53.

Cite this article as: Meghani $\mathrm{P}$, Shah SR, Vyas RC, Parikh PM, Chudasama TJ. Study of various treatment modalities of caesarean scar pregnancy. Int J Reprod Contracept Obstet Gynecol 2022;11:21720. 